\title{
EXPERIMENTAL PULMONARY EDEMA BY THIOUREA COMPOUNDS AND HYALINE MEMBRANES OF THE HUMAN NEWBORN LUNGS
}

\author{
TOSHIO FUJIKURA \\ Department of Gynecology \& Obstetrics, \\ School of Medicine, Keio University
}

(Received on December 13, 1955)

The production of acute pulmonary edema by thiourea compounds provides a new method for the experimental study of the pulmonary pathology. The edema-producing property of thiourea has been known for a long time (Binet, 1893). More recently Richter and associates have studied the toxic effect of a variety of thiourea compounds. Alpha-Naphthyl-thiourea (ANTU) was found to be especially toxic for a variety of laboratory animals.

The characteristic finding in animals dying of acute poisoning was marked pulmonary edema and pleural effusion. Drinker and Latter studying the mechanism of action of ANTU in dogs and rats concluded that it acted specially on the pulmonary capillary endothelial cells to increase its permeability, which resulted in filling the air spaces with edema fluid.

Instead of oxygen poisoning which has been used to make experimental hyaline membranes, we tried this new method of thiourea compounds on the guinea pig.

The experimental production of pulmonary hyaline membranes from oxygen poisoning has been studied by many investigators since Pichotka produced it in 1940. De and Anderson have extensively surveyed the literature on this subject in a recent review. We have been impressed by the vascular factors involved in oxygen poisoning as the possible explanation for the production of capillary injury and the resultant pulmonary hyaline membranes.

It is apparent that one of the most important conclusions that can be drawn from the experimental data on oxygen poisoning and ANTU poisoning in regard to pulmonary pathology are the vascular changes. In our recent histochemical studies we have concluded that hyaline membranes of human newborn and of the guinea pig which had oxygen poisoning contain a moderate amount of

This study was done in the Department of Obstetrics, The Johns Hopkins University, Baltimore, Maryland, U.S.A. 
proteins (mucoprotein) coming from the serum. One of the most striking findings on histologic examination of experimental hyaline membranes is the intense capillary engorgement and the increase in weight; in other words, pulmonary edema. Hyaline membranes and edema are closely interrelated in the lungs of experimental animals, but human newborn shows a little different picture in pulmonary pathology. Table 1 gives the differences of histologic findings between human newborn and guinea pig in pulmonary hyaline membranes.

Table 1

Difference of pulmonary pathology in hyaline membranes between human newborn and guinea pigs

\begin{tabular}{c|c|c|c|c|c|c|c|c}
\hline \hline $\begin{array}{c}\text { Kinds of } \\
\text { hyaline } \\
\text { membrane }\end{array}$ & $\begin{array}{c}\text { Atelec- } \\
\text { tasis }\end{array}$ & $\begin{array}{c}\text { Edema } \\
\text { Paren- } \\
\text { chyma }\end{array}$ & $\begin{array}{c}\text { Mesen- } \\
\text { chyma }\end{array}$ & $\begin{array}{c}\text { Con- } \\
\text { gestion }\end{array}$ & $\begin{array}{c}\text { Hemor- } \\
\text { rhage }\end{array}$ & Infection & $\begin{array}{c}\text { Fibrin } \\
\text { Formation }\end{array}$ & $\begin{array}{c}\text { Amniotic } \\
\text { debris }\end{array}$ \\
\begin{tabular}{c|c|c|c|c|c|c} 
Human \\
$\begin{array}{c}\text { Newborn } \\
\vdots\end{array}$
\end{tabular} & + & - & + & + & $\begin{array}{c}\text { Some- } \\
\text { times }\end{array}$ & $\begin{array}{c}\text { Some- } \\
\text { times }\end{array}$ & - & + \\
Guinea Pig & - & + & + & + & Always & Frequent & + & - \\
\hline
\end{tabular}

The purpose of this study is to ascertain experimentally the relationship between the hyaline membranes and pulmonary edema.

\section{EXPERIMENTS AND RESULTS}

Experiments with phenyl thiourea poisoning at normal atomospheric conditions in guinea pigs:

Nine adult guinea pigs ( 5 males and 4 females) which weighed from 640 to 1040 grams were given a moderate amount of phenyl thiourea into the peritoneal cavity. The dosage of phenyl thiourea and the approximate survival time are shown in Table 2. Phenyl-thiourea was administered intraperitoneally through a small incision under ether anesthesia because propylene glycol which was used as a solvent for phenyl thiourea produced minimal toxic effects by themselves.

The animals appeared unaffected for about 5 to 6 hours when varying degrees of restlessness, lack of appetite, sleepiness, followed by periods of dyspnea were observed. The dyspnea increased with marked retraction of the thorax and finally death of the guinea pigs between 7 and 38 hours. Two guinea pigs survived over 90 hours and then killed. Routine autopsies were performed, and representative sections of the major organs were saved for microscopic study. An increase in weight of the lung was found, and in one 


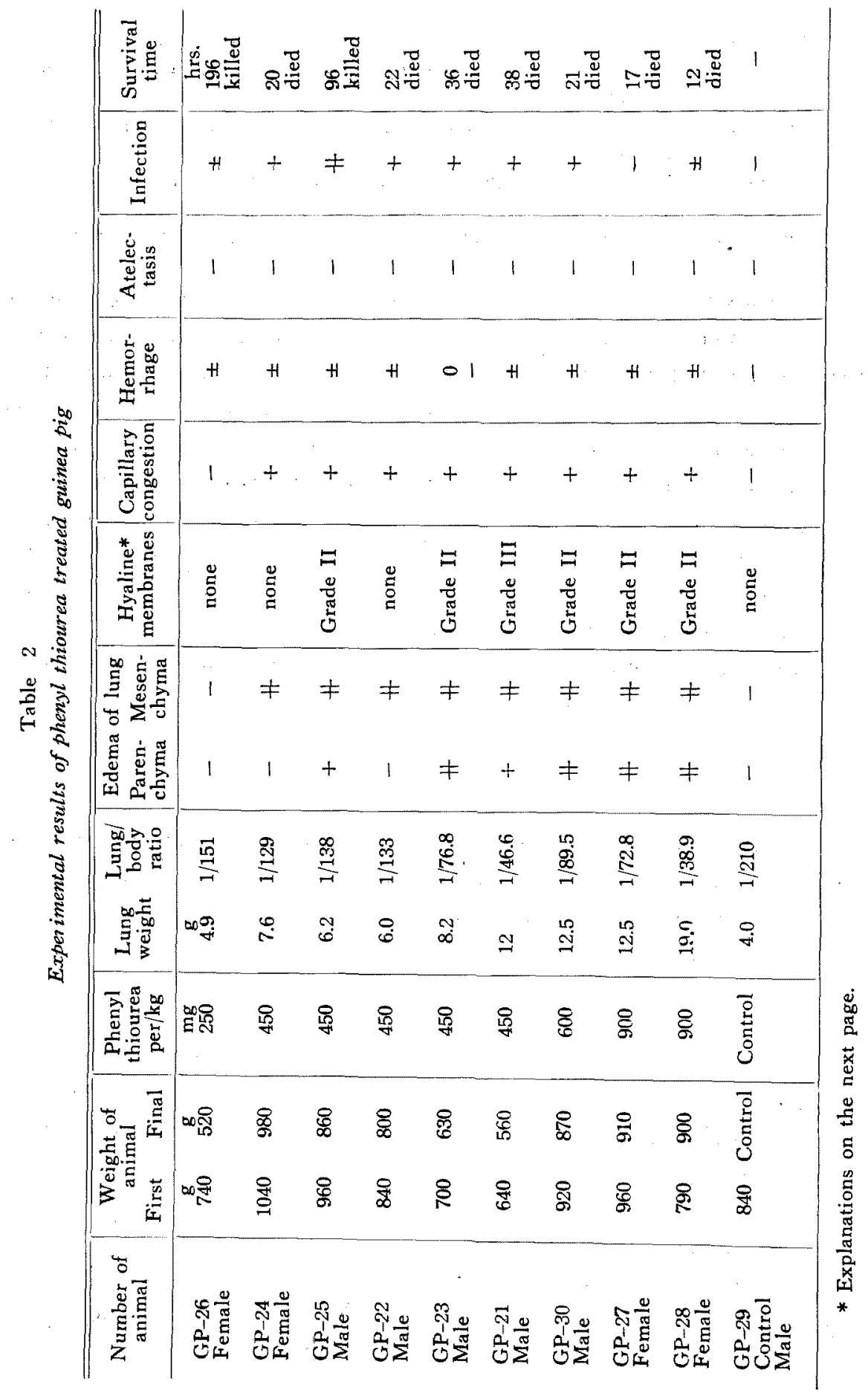


* Explanation concerning Table 2 on p. 193.

The following arbitrary grading system was devised by Dr. G. W. Anderson:

Grade I: Scattered irregular thin membranes in a few alveolar ducts and alveoli.

Grade II: Thin membranes with wide distribution in alveolar ducts and alveoli.

Grade III: Thicker membranes, well distributed in at least 75 per cent of the expanded alveolar ducts and alveoli.

Grade IV: Very thick membranes in all expanded alveolar ducts and alveoli.

instance the weight was 4.5 times that of the control animal. Histologic sections of the lungs revealed marked congestion of the pulmonary capillaries and varying degrees of polymorphonuclear leukocytic infiltrates in the alveolar spaces. A moderate amount of edematous fluid was also present in the alveoli. Edema of the pleura and perivascular spaces was pronounced. In six guinea pigs pulmonary hyaline membranes could be found varying from only a few alveoli to rather massive amounts. Four guinea pigs demonstrated congestion of pulmonary capillaries, but no evidence of hyaline membranes and edematous fluid in the alveoli. One interesting phase of this experiment was the presence of patchy localized edema with hyaline membranes.

The relationship between edema and hyaline membranes was closely observed. Adequate pulmonary edema was necessary to make hyaline membranes in guinea pigs.

\section{COMMENT}

As compared with the experimental findings of pulmonary hyaline membranes of human newborn, the following interesting points are discussed:

1. Significance of pulmonary edema.

2. Absorption of edema fluid.

3. Infection.

4. Atelectasis.

1. Significance of pulmonary edema: Pulmonary edema is the most important pathological picture in the lung of phenyl thiourea treated guinea pigs. Hyaline membrane is a kind of pathological change in the absorption of pulmonary edema, because lack of pulmonary edema is impossible in making hyaline membrane and to kill the animal. Pulmonary edema is considered as a cause of death in guinea pigs.

Pulmonary edema may be defined in a most general and basic way as an excessive accumulation of edema fluid in the pulmonary parenchyma or mesenchyma. For example, Henneman has defined acute pulmonary edema as 
a "syndrome characterized by the rapid flooding of the lung alveoli with serous or serosanguinous fluid". The clinical concept of pulmonary edema is that it is a syndrome due to excessive alveolar fluid and manifested by severe dyspnea, moist bubbling rales, hyperpnea, mounting cyanosis, frothy sputum, severe coughing, and a fairly consistent $x$-ray picture. Pulmonary edema of the newborn infant is different from the adult and the animal. It must be realized that pulmonary edema can occur without all of the above findings and even without any of them. Microscopically the absence of edema fluid is usual in the lung alveoli of human newborn, but the alveolar wall, the interlobular connective tissue and the pleura are frequently edematous.

When the lungs contain excess fluid, this fluid accumulates necessarily first in the tissue immediately about the lung capillaries. This means inside the alveolar walls and throughout the entire respiratory unit of the lung including the alveolar ducts, where transudated fluid at once appear in tissue containing lymph capillaries. The lung or the human newborn shows absence of edema fluid in the alveoli, but the edematous mesenchyma appears as a kind of pulmonary edema.

Fluid in the alveolar walls interferes with aereation of the blood. Fluid in the alveoli is even more effective.

When the baby has been aspirated, a moderate amount of amniotic fluid due to anoxic anoxia, the amniotic fluid mixes with the proteinized fluid delivered into the airway through leaky pulmonary capillaries. By Drinker's theory anoxia is a prime cause for leaky capillaries of the lung. The proteinized fluid reaching bronchioles is worst of all and blocks the divisions of alveoli. It is obvious that atelectasis occurs most easily if the tube to the alveolus is blocked. Atelectasis, in other words, inventilated areas of the lung makes more anoxia with alternation of the alveolar epithelium.

Many factors may be involved in causing pulmonary edema. Of these, Anoxia is prominent according to Drinker. Passage of edema fluid from the lung capillaries is brought about by the following factors:

1. Increased permeability of the wall of the capillaries.

2. Increased blood pressure in the pulmonary vessels.

3. Dilatation of the pulmonary blood vessels.

4. Lowered colloidal osmotic pressure of the lung.

5. Decrease in the lymphatic drainage of the lung.

These changes may result from a great variety of pathologic conditions which act singly or collectively,

1. Anoxia. 
2. Mechanical influences.

Congenital malformation of heart.

Aspirated amniotic fluid.

Primary or secondary atelectasis.

3. Neurogenic causes.

Brain injury, Cisternal injection of a fibrin-forming mixture,

bilateral vagotomy, etc.

4. Toxic agents.

Oxygen poisoning, aspiration of diluted hydrochloric acid, poisoning of thiourea compounds.

5. Inflammatory pulmonary changes.

6. Increased negativity of the intrapleural pressure.

7. Hypoproteinemia.

Premature baby., Liver disease.

8. Endocrine imbalance.

Excessive production of estrogen and progesterone causes

a decrease in the excretion of sodium.

9. Anaphylactic and allergic states.

10. Metabolic disturbance.

Diabetes, uremia, toxemia, etc.

2. Absorption of Edema fluid: Absorption of fluid and proteins from the lung is an important problem concerning anoxia, pulmonary edema, hyaline membrane and atelectasis. Since Colin found that a horse tolerated the intratracheal administration of 21 liters of water in $3 \frac{1}{2}$ hours without apparent ill effect, a number of investigators have confirmed the rapid absorption by the lower respiratory tract of protein-free saline or water. In such circumstances absorption mainly takes place directly into the pulmonary blood capillaries. Protein rich fluid in the alveoli, on the other hand, despite the profuseness of pulmonary lymphatics, is much more slowly absorbed than saline or water. By Courtice the time required for removal, in unanesthetized rabbits, of $6 \mathrm{ml}$ serum or plasma/Kg body weight was: from the lungs, 3 to 5 days, from the pleural cavity, 24 hours, from the peritoneal cavity, 8 hours. Fox concluded, from his own experiments and from a review of the literature that the lungs were only slightly permeable to antibody protein, homologous or heterologous, injected intratracheally. Drinker and Hardenbergh injected dye-labelled dog plasma and solutions containing purified bovine plasma albumin and crystalline egg albumin intratracheally in anesthetized dogs. Positive pressure artificial respiration was used to promote lymph movement and lymph collected from thoracic and right. 
lymph ducts. No dog plasma albumin and only traces of foreign albumin were detectable in the right duct lymph, none in thoracic duct lymph or blood stream.

Vascular reabsorption is prevented by the high concentration of protein which can be removed only by lymphatic absorption. It is possible that removal by cells or proteiolysis also plays a part. Drinker and Hardenbergh felt that the principal barrier to entrance into the lung of protein-containing fluids in the alveoli was the "epithelial lining" of the alveolar sacs. "Whether or not there is a continuous cellular barrier lining the alveoli is open to question. At the same time they have pointed out that there are no lymph capillaries in the alveolar walls where blood capillaries are maximally numerous.

It is thus apparent that proteins-derived from the blood and alveolar inhaled foreign particles must often have a minute, but appreciable, period of travel in the lung tissue before a lymphatic is reached and the material finds its way through the endothelium into the vessel.

These descriptions simply demonstrate the fact that watery solutions containing protein are removed in scant amounts and very slowly from the lungs.

This is an important problem to understand the pulmonary pathology of hyaline membranes.

3. Infection: Moderate amounts of polymorphonuclear leukocytes, Iymphocytes and monocytes are found in the lungs of these experimental animals. We are impressed that pulmonary edema and pneumonia are frequently found together at post-mortem examination. The presence of pneumonia may facilitate the development of pulmonary edema, and the presence of pulmonary edema may facilitate the development of pneumonia.

Microscopic examination: Compared with pneumonia of the newborn infant, it usually reveals a little different picture. By Potter the following points are described in the newborn infant: "Extravasation of red cells are occasionally found, but fibrin is rarely present in lungs involved by pneumonia of intrauterine origin. When pneumonia originates after birth, fibrin is common." No fibrin stain reaction has been positive in hyaline membranes of human newborn by many investigators. So this finding is very interesting to understand the relationship between hyaline membranes and amniotic fluid.

4. Atelectasis: Many investigators have been able to produce hyaline membranes, especially in guinea pigs, with several kinds of techniques, but they have rarely succeeded, as far as we can ascertain, in the production of any appreciable degree of associated atelectasis.

In this experiment the alveoli are dilated with edema fluid and no evidence of atelectasis is found. De and Anderson described recently in their experimental 
work, "although oxygen poisoning will produce hyaline membranes in adult guinea pigs and rats, there is rarely any associated atelectasis. Newborn guinea pigs and rats, however, react to oxygen poisoning with the full picture of hyaline membrane plus atelectasis in the majority of cases. This suggests some special predisposition on the part of the newborn lung to this entity."

The following factors may be present:

1. Primary atelectasis.

2. Pulmonary edema.

3. Resorption atelectasis.

4. Elasticity of the lung.

5. Lack of collateral respiration.

Fig. 1 shows a circular relationship of anoxia in the hyaline membrane disease of human newborn.

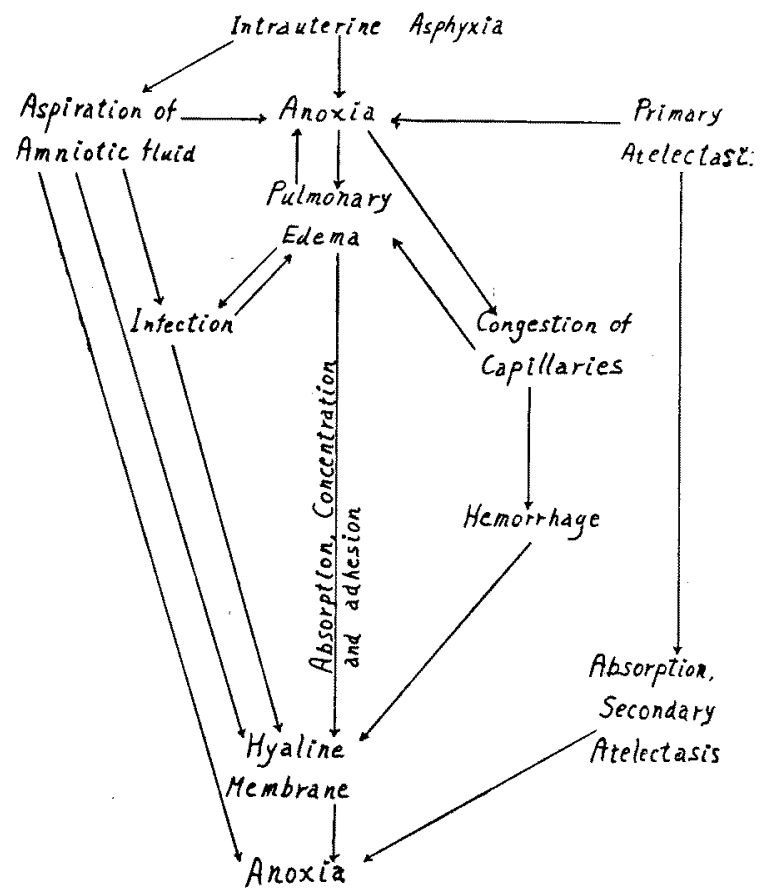

Fig. 1. The circle of anoxia in the hyaline membrane of newborn infant

\section{SUMMARY}

1. The lungs of phenyl thiourea treated guinea pigs show marked edema associated with hyaline membranes. 
2. Adequate edema fluid is necessary to make the hyaline membranes of guinea pigs.

3. The hyaline membranes are considered as a stadium of the absorption or the concentration in pulmonary edema.

4. Pulmonary edema and pneumonia are closely interrelated even in the animals.

5. Pulmonary edema is a cause of death in the animals, just as atelectasis is significant in the human newborn infant.

6. Pulmonary edema of human newborn infant should be carefully observed in the mesenchyma of the lungs.

I am grateful to Dr. G. W. Anderson for his generous cooperation and suggestions.

\section{BIBLIOGRAPHY}

1. Binet, P.: Rescherches pharmacologiques sur quelques urethanes et sur la thiourea. Rev. Med. de la Suisse Romande, 13:628, 1893.

2. Cameron, G. R., and De, S. N.: Experimental pulmonary edema of nervous origin. J. Path. and Bact., 61:375, 1949.

3. Colin, G.: Traité de physiologie Comparee des Animaux (2nd ed.). Paris: Bailliere, 1873, Vol. 2.

4. Courtice, F. C., and Simmonds, W. J.: Absorption from the lungs. J. Physio, 109:103, 1949.

5. Courtice, F. C., and Simmonds, W. J.: Physiological significance of lymph drainage of the serous cavities and lungs. Physiological Reviews $34: 419,1954$.

6. Drinker, C. K.: Pulmonary edema and inflammation. Harvard Univ. Press, 1950.

7. Drinker, C. K.: The clinical physiology of the lungs. Charles C. Thomas, 1954.

8. Drinker, C. K., and Hardenbergh, E.: Acute effects upon the lungs of dogs of large intravenous doses of alpha-naphthyl thiourea (ANTU). Am. J. Physiol., $156: 35,1949$.

9. Drinker, C. K., and Hardenbergh, E.: Absorption from the pulmonary alveoli. J. Exper. Med., 86:7, 1947.

10. Drinker, C. K., and Warren, M. F.: The genesis and resolution of pulmonary transudates and exudates. J. A. M. A., 122:269, 1943.

11. Drinker, C. K., Warren, M. F., and MacLanahan, M.: The absorption of protein solutions from the pulmonary alveoli. J. Exper. Med., 66:449, 1937.

12. Fujikura, T.: Histochemical studies of pulmonary hyaline membranes. Prepare to print.

13. Henneman, P.: Acute pulmonary edema with special reference to experimental studies. New England J. Med., 235:590, 1946.

14. Hesse, F. E., and Clayton, G. L.: The lining of the alveoli in mice, rats, dogs and frogs following acute pulmonary edema produced by ANTU poisoning. Anat. Record., 105:299, 1949.

15. Latta, H.: Pulmonary edema and pleural effusion produced by acute alphanaphthyl 
thiourea poisoning in rats and dogs. Bull. Johns Hopkins Hosp., 80:181, 1947. 16. Potter, E. L.: Pathology of the fetus and the newborn. The Year Book Publishers, P. 254, 1952.

17. Reutter, F.: Uber hyaline membranen und Atelektasen der Neugeborenen-Lunge. Gynaecologia 137:367, 1954.

18. Richter, C. P.: The development and use of alpha-naphthyl thiourea (ANTU) as a rat poison. J. A. M. A. 129:927, 1954.

19. Richter, C. P., and Clisby, K. H.: Toxic effects of the bitter-tasting phenylthiocarbamide. Arch. Path., 33:46, 1942.

20. Richter, C. P., and Clisby. K. H.: Graying of hair produced by ingestion of phenylthiocarbamide. Proc. Soc. Exp. Biol. and Med., 48:684-687, 1941.

21. Robin, E. D., and Thomas, E. D.: Some relations between pulmonary edema and pulmonary inflammation (Pneumonia). Archives of Internal Medicine 93:713, 1954.

22. De, Tran-Dinh, and Anderson, G. W.: Hyaline-like membranes associated with disease of the newborn lungs: A review of the literature. Obstetrical and Gynecological Survey 8:1, 1953.

23. De, Tran-Dinh, and Anderson, G. W.: The experimental production of pulmonary hyaline-like membranes with atelectasis. Am. J. of Obstetrics and Gynecology $68: 1557,1955$. 